\title{
Twinning: Coronary Artery Disease in Monozygotic Twins
}

\author{
Megan C. Smith ${ }^{1}$, John R. Baker ${ }^{2}$, Evan Gleaves ${ }^{3}$, Aniruddha Singh ${ }^{1}$, Mohammed Kazimuddin ${ }^{1}$ \\ 1. Cardiology, University of Kentucky, Bowling Green, USA 2. Cardiology, University of Kentucky School of Medicine, \\ Bowling Green, USA 3. Internal Medicine, University of Kentucky, Bowling Green, USA
}

Corresponding author: Mohammed Kazimuddin, mohammedkazimuddin65@gmail.com

\begin{abstract}
We present the case of a patient whose monozygotic twin brother suffered a fatal myocardial infarction at the age of 40 . The patient presented with similar symptoms as his brother. Given the family history, ischemic evaluation was undertaken and revealed similar coronary anatomy and severe coronary artery disease $(\mathrm{CAD})$. We review the current literature regarding genetic and environmental factors regarding coronary anatomy, locations of atherosclerotic lesions, and screening in twins.
\end{abstract}

Review began 06/15/2021 Review ended 06/24/2021 Published 07/03/2021

\section{○ Copyright 2021}

Smith et al. This is an open access article distributed under the terms of the Creative Commons Attribution License CC-BY 4.0., which permits unrestricted use, distribution, and reproduction in any medium, provided the original author and source are credited.
Categories: Cardiac/Thoracic/Vascular Surgery, Cardiology, Preventive Medicine

Keywords: multivessel coronary artery disease (mvcad), genetics of coronary artery disease, monozygous twins, coronary artery intervention, coronary artery angiography

\section{Introduction}

Cardiovascular disease continues to be the leading cause of mortality in the United States. By 2030, 40.5\% of the United States population is estimated to have coronary artery disease (CAD), with a projected direct medical cost of $\$ 818$ billion [1]. Clinical practices are continuing to evolve toward understanding genetic influence on disease and the application of that data on diagnosing and treating illnesses, and preferably predicting and interceding before symptoms begin or pathology occurs. The development of CAD involves a multifaceted interaction between environmental and genetic factors, with premature CAD involving a powerful, yet not completely understood, genetic element [2]. In this report, we present a case of monozygotic twins with similar coronary anatomy and atherosclerotic lesions.

\section{Case Presentation}

A 42-year-old Caucasian man (twin A) presented to our clinic complaining of lower extremity edema and dyspnea beginning several weeks prior. His past medical history included chronic pancreatitis and insufficiency, diabetes mellitus type one, and former alcohol and cocaine abuse with last use 10 years prior. He also suffered from uncontrolled hypertension despite compliance with his medication. His medications included amlodipine $10 \mathrm{mg}$ daily, lisinopril $40 \mathrm{mg}$ daily, hydralazine $25 \mathrm{mg}$ twice daily, and hydrochlorothiazide $25 \mathrm{mg}$ daily. His family history was significant for a monozygotic twin brother (twin B) who suffered a fatal myocardial infarction (MI) at the age of 40; there was no evidence of premature CAD in any other close relative. Twin B had similar symptoms prior to MI that prompted twin A to present. The decision was made to proceed with ischemic evaluation for twin A given the family history and presenting symptoms.

2-D echocardiogram revealed normal ejection fraction, normal wall motion, moderate left ventricular hypertrophy, grade one diastolic dysfunction, and mild mitral regurgitation. Regadenoson stress testing revealed a large area of moderate ischemia involving the entire inferior wall and inferoseptal wall with associated moderate hypokinesis of the inferior and inferoseptal walls. This was followed by diagnostic coronary angiography which revealed a left dominant circulation and severe triple vessel CAD. There was $50 \%$ stenosis of the proximal segment and $80 \%$ focal stenosis of the distal segment of the dominant left circumflex artery (LCX), 90\% mid-segment stenosis of the posterior descending artery (PDA), and 100\% midsegment occlusion of the right coronary artery (RCA). Finally, the procedure revealed ostial and proximal $40 \%$ stenosis and $90 \%$ mid-segment stenosis of the left anterior descending artery (LAD). Twin B's coronary angiography (performed two years prior to twin A's presentation) revealed 99\% stenosis in the left PDA of the dominant LCX, $90 \%$ mid-segment stenosis of the RCA, and a prior stent occluded with thrombus in the LAD (Figures 1-3). 


\section{Cureus}

Twin A
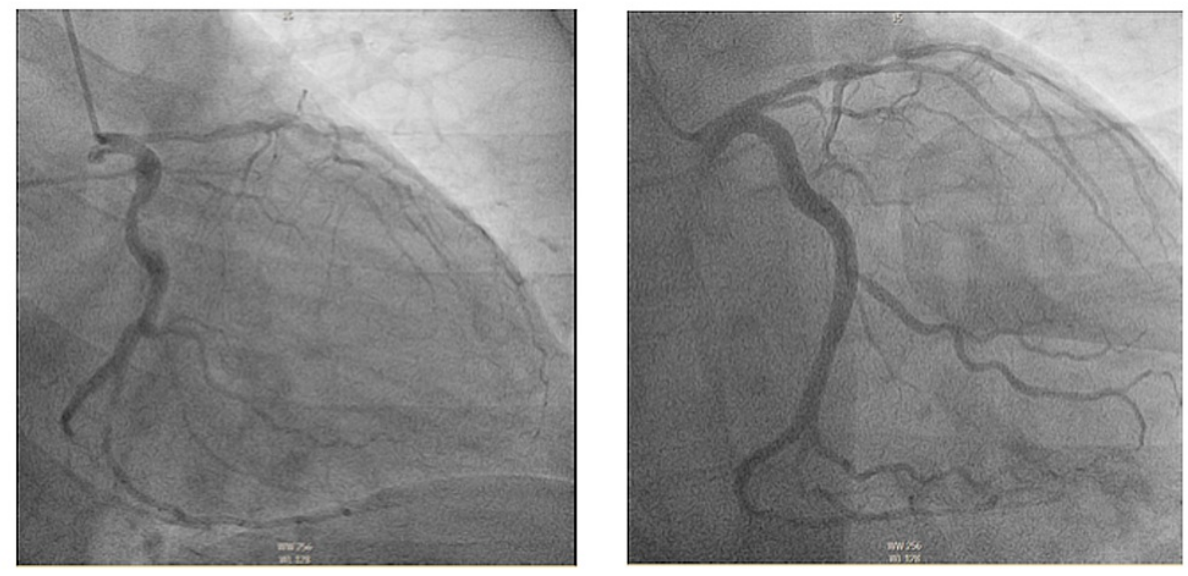

FIGURE 1: Coronary angiogram in right anterior oblique projection with caudal angulation providing visualization of the left main artery, left circumflex artery, and left anterior descending artery.

Twin A

Twin B
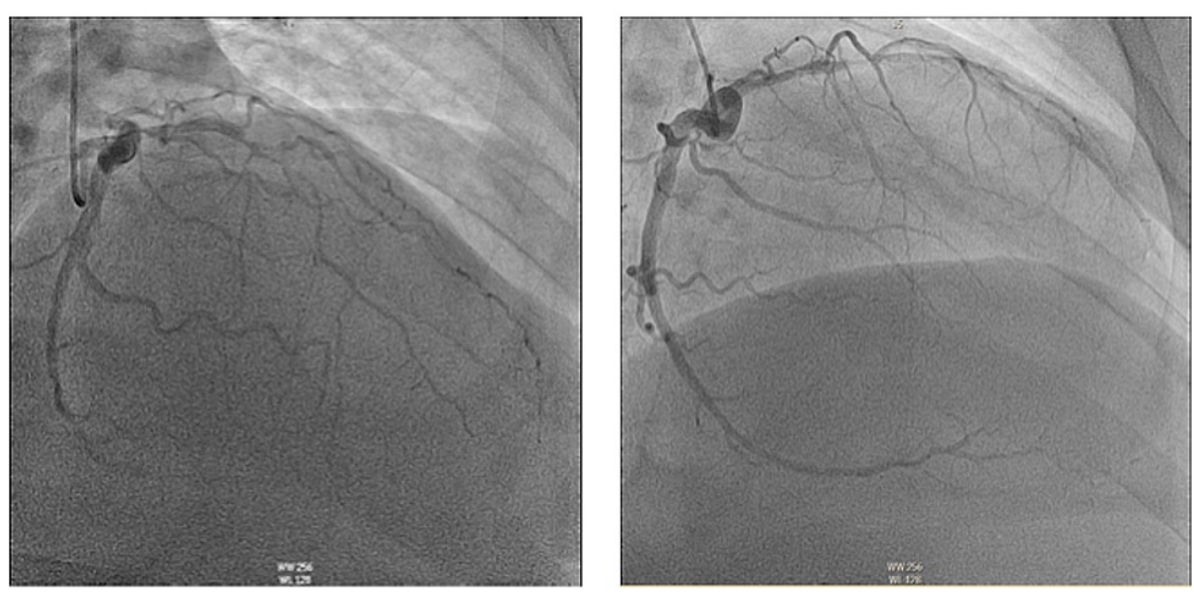

FIGURE 2: Coronary angiogram in right anterior oblique projection with cranial angulation providing visualization of the left circumflex artery and left anterior descending artery. 


\section{Cureus}

Twin A

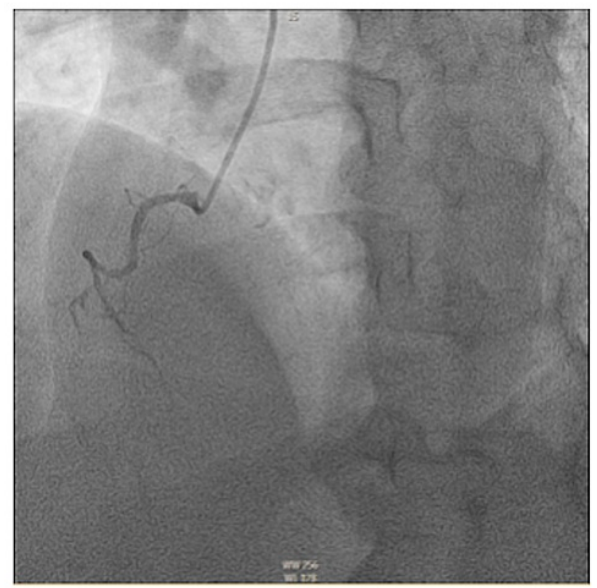

Twin B

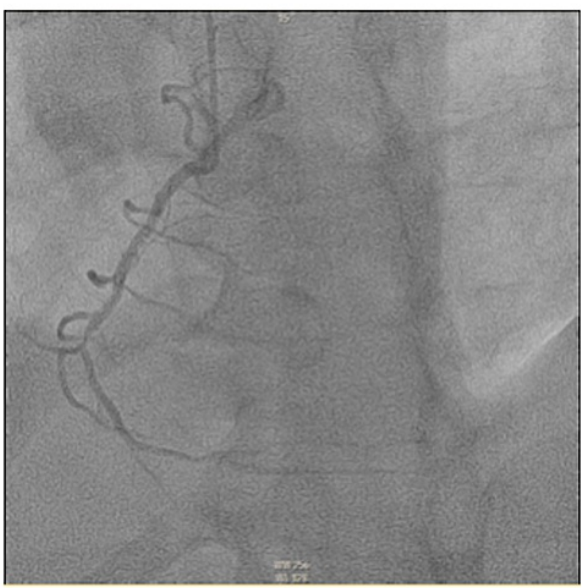

\section{FIGURE 3: Coronary angiogram in left anterior oblique projection providing visualization of the right coronary artery.}

Twin A was referred for cardiothoracic surgery evaluation. He underwent coronary artery bypass grafting with grafts including left internal mammary artery to LAD and independent reversed saphenous vein grafts from aorta to diagonal branch and obtuse marginal branches. Eight weeks into recovery, his presenting complaints of dyspnea and lower extremity edema had completely resolved.

\section{Discussion}

The genetic and environmental contributions to the development of CAD is not fully detailed, but investigations are currently underway. There are at least 36 loci that have been identified as susceptible to contributing to $\mathrm{CAD}$ due to single nucleotide polymorphisms [3]. The genetic heritability of the locations of atherosclerotic lesions in $\mathrm{CAD}$ is not fully known, but the preponderance of growing reports of $\mathrm{CAD}$ in identical twins as in our case suggests that proximal stenoses have a higher degree of heritability when compared to distal lesions [4-13], with ostial and left main CAD seemingly having the greatest genetic contribution to their frequency in monozygous twin populations [13]. Both of our patients had leftdominant coronary systems, which is present is roughly $9.1 \%$ of the population and not known to be concordant in twins $[13,14]$. It is possible that a different etiology for the development of proximal versus distal coronary artery atherosclerosis produces the varying heritability [15]. The high degree of similarity of lesions in our case supports the conclusions regarding the extent of heritability of CAD lesions and their locations. However, it has been proposed that an assortment of elements such as hemodynamic factors, particularly changes of arterial shear stress, are responsible for this phenomenon [16].

Despite the uncertainty regarding the heritability of atherosclerotic lesion location, the risk of CAD in a monozygotic twin whose twin has CAD, despite their personal or modifiable risk factors, is well-established. Results from a widely cited Swedish study demonstrate that if a male twin dies of a myocardial infarction, his living twin has a $50 \%$ chance of dying from CAD by the time he is 55 years of age, which is a twentyfold increase when compared to the general population $[17,18]$. The genetic contribution to CAD is more pronounced the younger a twin is who suffers a fatal MI, indicating an increased risk of death due to MI for the living twin. The older a twin is who suffers a fatal MI, the less likely their living twin will also die from $\mathrm{CAD}$, suggesting the environmental component is a stronger contributor in those instances. Female twin data follows similar trends [18]. Regardless of young age and absence of symptoms, the likelihood of uncovering occult $\mathrm{CAD}$ is as high as 50\% in asymptomatic twins of symptomatic patients [5], therefore serious consideration should be given towards screening asymptomatic twins of symptomatic patients $[5,13,18-20]$ as is supported by our case.

\section{Conclusions}

Case reports such as ours provide evidence for the genetic contribution in the development of CAD. While lesion locations are not fully dependent on genetics, certain locations do have a notable degree of heritability. The similar location of stenosis, age at first cardiac event, and risk factor profiles show concordance in this pair of identical twins. Our report highlights the importance of closely monitoring the family members of patients with CAD, particularly if they are monozygotic twins.

\section{Additional Information}




\section{Disclosures}

Human subjects: All authors have confirmed that this study did not involve human participants or tissue. Conflicts of interest: In compliance with the ICMJE uniform disclosure form, all authors declare the following: Payment/services info: All authors have declared that no financial support was received from any organization for the submitted work. Financial relationships: All authors have declared that they have no financial relationships at present or within the previous three years with any organizations that might have an interest in the submitted work. Other relationships: All authors have declared that there are no other relationships or activities that could appear to have influenced the submitted work.

\section{References}

1. Heidenreich PA, Trogdon JG, Khavjou OA, et al.: Forecasting the future of cardiovascular disease in the United States: a policy statement from the American Heart Association. Circulation. 2011, 123:933-44. 10.1161/CIR.0b013e31820a55f5

2. Arnett DK, Baird AE, Barkley RA, et al.: Relevance of genetics and genomics for prevention and treatment of cardiovascular disease: a scientific statement from the American Heart Association Council on Epidemiology and Prevention, the Stroke Council, and the Functional Genomics and Translational Biology Interdisciplinary Working Group. Circulation. 2007, 115:2878-901. 10.1161/CIRCULATIONAHA.107.183679

3. Roberts R, Stewart AF: Genetics of coronary artery disease in the 21st century . Clin Cardiol. 2012, 35:53640. 10.1002/clc.22002

4. Kreulen TH, Cohn PF, Gorlin R: Premature coronary artery disease in identical male twins studied by selective coronary arteriography. Cathet Cardiovasc Diagn. 1975, 1:91-6. 10.1002/ccd.1810010112

5. Samuels LE, Samuels FS, Thomas MP, et al.: Coronary artery disease in identical twins . Ann Thorac Surg. 1999, 68:594-600. 10.1016/s0003-4975(99)00629-3

6. Russo P, Steffenino G, Dellavalle A, Ribichini F: Concomitant myocardial infarction in identical twins with similar coronary lesions. G Ital Cardiol. 1995, 25:341-3.

7. Frings AM, Mayer B, Böcker W, Hengstenberg C, Willemsen D, Riegger GA, Schunkert H: Comparative coronary anatomy in six twin pairs with coronary artery disease. Heart. 2000, 83:47-50. 10.1136/heart.83.1.47

8. Schilling RJ, Norell MS: Coronary artery disease in identical twins . Eur Heart J. 1995, 16:134-5. 10.1093/eurheartj/16.1.134

9. Herrington DM, Pearson TA: Clinical and angiographic similarities in twins with coronary artery disease . Am J Cardiol. 1987, 59:366-7. 10.1016/0002-9149(87)90819-8

10. Nathoe HM, Stella PR, Eefting FD, et al.: Angiographic findings in monozygotic twins with coronary artery disease. Am J Cardiol. 2002, 89:1006-9. 10.1016/s0002-9149(02)02262-2

11. Holmes DR Jr, Kennel AJ, Smith HC, Gordon H, Moore SB: Coronary artery disease in twins . Br Heart J. 1981, 45:193-7. 10.1136/hrt.45.2.193

12. Kaluźa G, Abukhalil JM, Raizner AE: Identical atherosclerotic lesions in identical twins. Circulation. 2000, 101:E63-4. 10.1161/01.cir.101.4.e63

13. Fischer M, Broeckel U, Holmer S, et al.: Distinct heritable patterns of angiographic coronary artery disease in families with myocardial infarction. Circulation. 2005, 111:855-62. 10.1161/01.CIR.0000155611.41961.BB

14. Knaapen $\mathrm{M}$, Koch $\mathrm{AH}$, Koch C, et al.: Prevalence of left and balanced coronary arterial dominance decreases with increasing age of patients at autopsy. A postmortem coronary angiograms study. Cardiovasc Pathol. 2013, 22:49-53. 10.1016/j.carpath.2012.02.012

15. von Lüdinghausen M: The clinical anatomy of coronary arteries . Adv Anat Embryol Cell Biol. 2003, 167:IIIVIII, 1-111. 10.1007/978-3-642-55807-8

16. Bogaty P, Brecker SJ, White SE, Stevenson RN, el-Tamimi H, Balcon R, Maseri A: Comparison of coronary angiographic findings in acute and chronic first presentation of ischemic heart disease. Circulation. 1993, 87:1938-46. 10.1161/01.cir.87.6.1938

17. Turley AJ, Chen V, Hall JA: Simultaneous presentation of coronary heart disease in identical twins . Postgrad Med J. 2008, 84:100-2. 10.1136/pgmj.2007.064493

18. Marenberg ME, Risch N, Berkman LF, Floderus B, de Faire U: Genetic susceptibility to death from coronary heart disease in a study of twins. N Engl J Med. 1994, 330:1041-6. 10.1056/NEJM199404143301503

19. Douglas H, Hanratty CG, Herity NA: Coronary artery disease: anatomy and presentation in identical twins . Ulster Med J. 2009, 78:187-8.

20. Clement A, Picard F, Varenne O: Myocardial infarction in monozygotic twins. BMJ Case Rep. 2020, 13:10.1136/bcr-2020-238272 